\title{
Effect of Saccharomyces cerevisiae - Induced Fermentation on the Antioxidant Property of Roselle Calyx Aqueous Extract
}

\author{
Chizoba K. Ejuama, Benjamin C. Onusiriuka, Victoria Bakare, \\ ThankGod O. Ndibe, Magaji Yakubu, and Enemona G. Ademu
}

\section{ABSTRACT}

This study investigated the effects of Saccharomyces cerevisiae-induced fermentation on the antioxidant properties of Roselle calyx aqueous extract and determined the physicochemical changes of the fermented extract. Total phenolics, total flavonoid, ascorbic acid content, total monomeric anthocyanin content and DPPH radical scavenging activity of roselle aqueous extract were investigated before and after fermentation. Roselle calyx aqueous extract was fermented for period of 10 days. During fermentation, the extract was evaluated for $\mathrm{pH}$, alcohol (\%), titratable acidity $(\%)$ and total soluble solids ( $\left.{ }^{\circ} \mathrm{Brix}\right)$. Total soluble solids and $\mathrm{pH}$ significantly decreased at the end of the fermentation whereas titratable acidity and alcohol content significantly increased. Fermentation caused significant reduction in total monomeric anthocyanin content from an initial value of $3518 \pm 30.8$ to $1075 \pm 28.2 \mathrm{CGE} / 100 \mathrm{~g}$ dry extract whereas significant increase was observed in total phenolic content from $195.75 \pm 76.01$ to $455.5 \pm 1.41 \mathrm{mgGAE} / 100 \mathrm{~g}$ dry extract and ascorbic acid content from $1392 \pm 101$ to $2028 \pm 108 \mathrm{mg} \mathrm{AAE} / 100 \mathrm{~g}$ dry extract and total flavonoids increased from 193.0 \pm 74.25 to $291.5 \pm 4.95$ mgQE/100 g dry extract but it was not significant. There was also a significant increase in 1-1-diphenyl-2-picryl hydrazyl (DPPH) scavenging activity of roselle calyx aqueous extract from an initial value of $44.15 \%$ to final value of $71.10 \%$ after fermentation, leading to an increase in antioxidant activity. Therefore, the quantity of phenolic compounds increased with fermentation process. This study showed that roselle calyx aqueous extract fermented by Saccharomyces cerevisiae has a better antioxidant activity.

Keywords: Antioxidants, Fermentation, Roselle Calyx, Saccharomyces cerevisiae.

\section{INTRODUCTION}

Fermentation is a biotechnological technique in which microorganism-producing enzymes are used to develop new products with modified properties. Research has shown that fermentation of food can cause biochemical changes which in turns helps to improves/ maintains the nutritional, shelf-life and sensory properties of food. The extent of changes that could occur during fermentation of food depends upon the microbial enzymes active in the food and the environmental factors that affects the growth of the organism and its enzymatic activities [1].

Yeasts are unicellular microorganisms that belong to the division of fungi known as the Ascomycota and fungi imperfecti. In thousands of years, yeasts have been known to humans as they have been used to carry out fermentation
Published Online: May 31, 2021

ISSN: 2684-5199

DOI: $10.24018 /$ ejbio.2021.2.3.201

Chizoba K. Ejuama*

Nigerian Defence Academy, Kaduna, Nigeria.

(e-mail: ejuamachizoba@gmail.com) Benjamin C. Onusiriuka

Nigerian Defence Academy, Kaduna, Nigeria.

(e-mail: benjaminonusiriuka@ gmail.com) Victoria Bakare

Nigerian Defence Academy, Kaduna, Nigeria.

(e-mail: bakarevictoria2@gmail.com) ThankGod O. Ndibe

Nigerian Defence Academy, Kaduna, Nigeria.

(e-mail: tgodndibe@gmail.com)

Magaji Yakubu

Nigerian Defence Academy, Kaduna, Nigeria.

(e-mail: magajiyakubu01@gmail.com) Enemona G. Ademu

Nigerian Defence Academy, Kaduna, Nigeria.

(e-mail: enemonagreg@ gmail.com)

*Corresponding Author

process of alcoholic beverage and leavening bread [2]. Fruit juice has been used to produce alcoholic beverage using Saccharomyces cerevisiae strains and each strain has its own characteristics and impacts special properties [3]. Saccharomyces cerevisiae strains have been reported to be best in ethanol tolerance and production [4].

Hibiscus sabdariffa Linn is a shrub that is commonly known as roselle, which is a member of Malvaceae family. It is cultivated in many areas, including Africa and Central America despite being native to Asia [5]. Roselle is of great economic importance, although it is yet to be fully exploited. The calyces of roselle are used in the preparation of a local refreshing beverage in Nigeria called Zobo. Roselle calyces have been reported to contain dry matter, crude fibre content, crude protein content, ash content and moisture content values were $40.45 \%, 20.83 \%, 27.32 \%, 4.67 \%$ and $6.79 \%$, 
respectively [6]. Roselle calyx is considered to be good sources of invaluable antioxidants.

Antioxidants are molecules that guard cells against the harmful effects of free radicals, thus balancing oxidative stress [7]. Roselle's antioxidant activity is largely attributed to the phenolic compounds present in roselle plant [8]. Frank et al [9] studied the influence of roselle water extract on specific antioxidant status in human body; the report proved that the extract boosts systematic antioxidant strength and also moderates oxidative stress in the body. Research has shown that roselle calyx extract have high antioxidant activity potential and numerous health benefits, surprisingly little attention is channeled on its study. These gaps give an opportunity for investigating the impact of fermentation on the phenolic compounds in roselle calyces. Thus, the objective of this present work is to evaluate the effect of controlled fermentation using Saccharomyces cerevisiae on the antioxidant property of roselle calyx aqueous extract as well as determination of physicochemical changes of the fermented extract.

\section{MATERIALS AND MethodS}

\section{A. Sample Collection}

Fresh Roselle calyces (Hibiscus sabdariffa) were collected in a clean foil paper from a garden at Barnawa Kaduna, Kaduna State Nigeria. The collected sample was transported to Biotechnology laboratory. The Roselle calyx was identified at herbarium section of the Department of Biological Sciences of Nigerian Defence Academy, Kaduna. The sample was air dried at room temperature.

\section{B. Proximate Composition of Roselle Calyx}

Roselle calyx (NDABIOH202101) sample was analyzed proximately for moisture content, crude protein, ash, crude lipid and crude carbohydrate using standard methods [10].

\section{Sample Processing}

Roselle calyx (NDABIOH202101) extract was prepared by boiling $200 \mathrm{~g}$ of dried calyces with $1 \mathrm{~L}$ of distilled water for 15 minutes using low heat. The boiled roselle juice was filtered by passing it through a sieve to remove the calyces. The physicochemical properties and phytochemical contents of the extract were analyzed and recorded prior to fermentation.

\section{Isolation and Identification of Yeast Strain used for Fermentation}

For the screening of yeast strain used for the controlled fermentation, fresh palm wine was purchased from rural seller shop in Sabo-Tasha Kaduna, Kaduna state. Standard dilution plate count technique was used to obtain the yeast isolates. Adopting the method of Martini et al [11] serial dilution of the fresh palm wine sample was prepared using distilled water as diluents. Pure colonies obtained were transferred onto a Yeast Extract Peptone Glucose (YEPG) agar slants for subsequent identification and stored in the refrigerator at $4{ }^{\circ} \mathrm{C}$. Macroscopic and microscopic identification of Saccharomyces cerevisiae was done following Barnett et al [12]. Sugar fermentative test, temperature tolerance test, ethanol tolerance test was carried out using the method of Thais et al. [13], after which molecular identification of the isolates was done. The DNA extraction of the isolate was performed using AccuPrep Genomic DNA Extraction Kit protocol (K-3032) following the manufacturer's instructions. PCR was done using universal primers for fungi (ITS1 5'TCCGTAGGTGAACCTGCGG-3' and ITS4 5TCCTCCGCTTATTGATATGC-3) while Dye terminator cycle sequencing was done using quick start kit with the primers (NL1

5 GCATATCAATAATAAGCGGAGGAAAAG-3' and NL4 5'-GGTCCGTGTTTCAAGACGG-3').

\section{E. Fermentation of Roselle Calyx Aqueous Extract}

The extract was adjusted by increasing the sugar level to $20.35^{\circ}$ Brix and extract was pasteurized at $50{ }^{\circ} \mathrm{C}$ for 30 minutes. Sodium metabusulphite $60 \mathrm{mg} / \mathrm{l}$ was added to stabilize the extract. Fermentation was conducted in $2 \mathrm{~L}$ fermentation vat plugged with cotton wool with cork through which fermenting lock was inserted, the fermentation vat contained $1 \mathrm{~L}$ of roselle extract inoculated with $1 \mathrm{~mL}$ of $24 \mathrm{~h}$ old broth culture of Saccharomyces cerevisiae $\left(>10^{5} \mathrm{cfu} / \mathrm{ml}\right)$. The fermentation process was carried out for 10 days and temperature was maintained at $30 \pm 2{ }^{\circ} \mathrm{C}$.

\section{F. Physicochemical Analysis}

Total soluble solid (TSS), $\mathrm{pH}$, titratable acidity, and alcohol content of the extract was determined prior to fermentation and during the fermentation period at an interval of 2 days. Titratable acidity of the extract was determined according to standard method of AOAC [14]. Acidity was determined by titration using $0.1 \quad \mathrm{~N} \quad \mathrm{NaOH}$ and phenolphthalein as an indicator. The $\mathrm{pH}$ was measured using pH meter. Total soluble solid was determined using a hand refractometer. Alcohol content was determined using in difference in the ${ }^{\circ}$ Brix.

\section{G. Determination of Ascorbic Acid Content}

The concentration of Vitamin $\mathrm{C}$ content in the roselle extract was analyzed before and after fermentation following Folin-Ciocalteu reagent spectrophotometer method. The sample $(20 \mathrm{ml})$ was pipette into $100 \mathrm{ml}$ volumetric flask and $10 \%$ TCA ( $2 \mathrm{ml})$ solution was also added, then distilled water was used to make it up to $100 \mathrm{ml}$. the mixture was shaken for 1minute and allowed to stand for 1minute before it was filtered into a conical flask using whatman filter paper. One millimeter of the sample, $3 \mathrm{ml}$ of distilled water and $0.4 \mathrm{ml}$ of Folin reagent were added into the test tube. The mixture was then incubated for 10 minutes at room temperature. Absorbance was read at $760 \mathrm{~nm}$ on the spectrophotometer. A standard curve was calibrated using ascorbic acid and the result was expressed in milligram of ascorbic acid per $100 \mathrm{~g}$ dry extract [15].

\section{H. Determination of Total Phenolic and Flavonoid Content}

Total phenolic content (TPC) of the roselle extract was analyzed with Folin-Ciocalteu reagent using the method of Mgaya et al. [15]. Three hundred microliter $(300 \mu \mathrm{l})$ of the sample (duplicate), $1.5 \mathrm{ml}$ of Folin-Ciocalteu's reagent (diluted 10 times) and $1.2 \mathrm{ml}$ of sodium carbonate $(7.5 \% \mathrm{w} / \mathrm{v})$ were added into tubes. The test tubes were incubated in the 
dark at room temperature and left for 30 minutes. Absorbance at $765 \mathrm{~nm}$ was read using UV spectrophotometer. The standard curve was calibrated using gallic acid and TPC was expressed in gallic acid. Aluminum chloride colorimetric method was used for flavonoid determination [16]. Two hundred and fifty microliters of the sample $(250 \mu \mathrm{L})$ were mixed with $1.25 \mathrm{ml}$ distilled water, $75 \mu \mathrm{L}$ of $5 \% \mathrm{NaNO}_{3}$ and $150 \mu \mathrm{L}$ of $10 \% \mathrm{AlCl}_{3}$ in test tubes. Absorbance at $510 \mathrm{~nm}$ was read against a blank. A standard curve was calibrated using quercetin. The concentration of total flavonoids was expressed in mg quercetin/ gram dry extract.

\section{Determination of Total Monomeric Anthocyanin}

Total monomeric anthocyanin (TMA) of the extract was analyzed prior to and after fermentation. Buffer solutions ( $\mathrm{pH}$ 1 and $\mathrm{pH} 5$ ) were prepared in different glass tubes and the sample $(200 \mu \mathrm{L})$ was introduced into the tubes and mixed properly. Absorbance was measured at two different wavelengths of $520 \mathrm{~nm}$ and $700 \mathrm{~nm}$ on the spectrophotometer against a blank (distilled water) [17]. The total monomeric anthocyanins were calculated using the formula:

$$
\begin{gathered}
\mathrm{A}=\left(\mathrm{A}_{520}-\mathrm{A}_{700}\right)_{\mathrm{pH}=1.0}-\left(\mathrm{A}_{520}-\mathrm{A}_{700}\right)_{\mathrm{pH}=4.5} \\
\text { TMA }(\mathrm{mg} / \mathrm{L})=\frac{A \times M W \times F \times 1000}{\varepsilon \times l}
\end{gathered}
$$

where

A = Difference of the absorbance $(520 \mathrm{~nm}$ and $700 \mathrm{~nm})$ of the different $\mathrm{pH}$;

MW = Molecular weight (449.2 gmole $^{-1}$ for cyanidin-3-Oglucoside);

$\varepsilon=$ Molar absorptivity $\left(26900 \mathrm{Lmole}^{-1} \mathrm{~cm}^{-1}\right)$;

$\mathrm{F}=$ dilution factor (total volume/volume of extract);

$1=$ the light path through the quartz cell $(1 \mathrm{~cm})$.

The result was expressed as mg equivalents of cyanidin-3O-glucoside. 100 g-1 of dry calyces.

\section{J. Determination of Radical Scavenging Activity}

Radical scavenging activity of roselle extract was estimated before and after fermentation using 2-2-diphenyl1 - picryl hydrazyl (DPPH). The sample $(0.1 \mathrm{ml})$ was pipette into $3.9 \mathrm{ml}$ DPPH in methanol which was freshly prepared and incubated in the dark for 45 minutes. Absorbance was read at $515 \mathrm{~nm}$ with spectrophotometer. DPPH $(3.9 \mathrm{ml})$ in 0.1 $\mathrm{ml}$ methanol served as the control [18]. Radical scavenging activity was calculated in percentage using the equation below:

DPPH radical scavenging activity $(\%)=$ $\left[1\right.$ - $^{\text {absorbance }_{\text {sample }} / \text { absorbance }}$ control $\left.)\right] \times 100$.

\section{K. Statistical Analysis}

Physicochemical analysis, total phenolic and flavonoids contents, total monomeric anthocyanin content and scavenging activity were expressed as mean \pm SD and analyzed using one-way analysis of variance (ANOVA) using SPSS program at $\mathrm{P}>0.05$.

\section{RESULTS}

\section{A. Morphological, Physiological and Molecular Identification of Yeast Isolates}

The result of this study showed that the colonies are creamy in colour. The microscopic morphology of the yeast isolates examined under light microscope with 100x magnification showed that have ovoid shapes (Fig. 1). The sugar fermentation test on the yeast isolates using six different sugars: glucose, galactose, maltose, sucrose, lactose and raffinose showed that the isolates gave positive reaction for all the sugars except lactose (Table I).

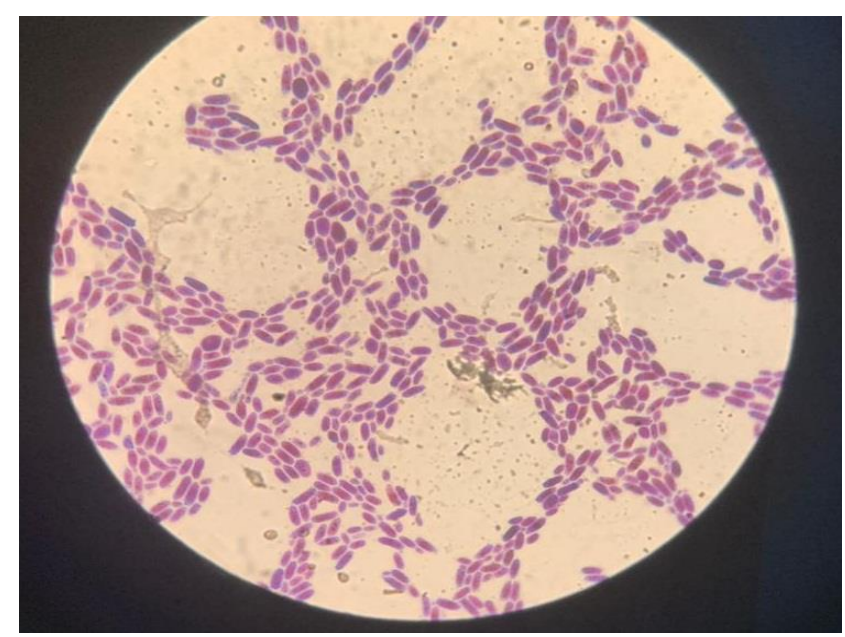

Fig. 1. Microscopic Morphology of Isolate A (Saccharomyces cerevisiae).

The effect of temperature $\left(25^{\circ} \mathrm{C}, 30^{\circ} \mathrm{C}, 37^{\circ} \mathrm{C}\right.$ and $\left.45^{\circ} \mathrm{C}\right)$ on the growth pattern of the isolates revealed that isolate $\mathrm{A}$ and $\mathrm{C}$ showed moderate growth at $45^{\circ} \mathrm{C}$ while isolate $\mathrm{B}$ and $\mathrm{D}$ showed low growth, and $\mathrm{E}$ showed no growth at $45^{\circ} \mathrm{C}$. More so, the effect of ethanol on the growth pattern of the isolates carried out at 10,13 and $15 \%$ ethanol revealed that $A$ and $\mathrm{E}$ showed an intensive growth on $15 \%$ ethanol while $\mathrm{B}$ and $\mathrm{C}$ showed moderate growth, and D showed low growth. The result of flocculation capacity of the yeast isolates revealed that $\mathrm{A}, \mathrm{B}$ and $\mathrm{E}$ have flocculation abilities while $\mathrm{C}$ and D showed no flocculation ability (Table I).

Isolate A was chosen for molecular study because of its ability to sugar fermentation and high tolerance to ethanol and temperature. Molecular identification showed that genomic DNA extraction from the cultured cell (Isolate A) was successful using PCR technique with univeral primer for fungi ITS1 and ITS4 (5'-TCCGTAGGTGAACCTGCGG-3 and 5'-TCCTCCGCTTATTGATATGC -3). The PCR product gave an estimated size of $500 \mathrm{bp}$ (Fig. 2). The sequence obtained for the gene was compared against the nonredundant nucleotidesequence collected at NCBI Genbank using the web interface of NCBI-BLAST. BLASTn analysis of the PCR product indicated that the sequence was is Saccharomyces cerevisiae M18 strain 26S ribosomal RNA gene, partial sequence and has $88.65 \%$ identity with $99 \%$ coverage to Saccharomyces cerevisiae, with E-value of $2 \mathrm{e}-$ 161 and was identified as Saccharomyces cerevisiae with ID GU080045.1 (Table II). 
TABLE I: MORPHOLOGY AND PHYSIOLOGICAL IDENTIFICATION OF THE YEAST ISOLATES

\begin{tabular}{|c|c|c|c|c|c|c|c|c|c|c|c|c|c|c|c|}
\hline \multirow{2}{*}{ Isolate } & \multirow{2}{*}{ Colour } & \multirow{2}{*}{ Shape } & \multirow{2}{*}{ Flocculation } & \multicolumn{5}{|c|}{ Sugar Fermentation } & \multicolumn{3}{|c|}{ Ethanol (\%) } & \multicolumn{4}{|c|}{ Temperature $\left({ }^{\circ} \mathrm{C}\right)$} \\
\hline & & & & Glu & Gal & Mal & Lac & Raf & $10 \%$ & $13 \%$ & $15 \%$ & 25 & 30 & 37 & 45 \\
\hline $\mathrm{A}$ & Creamy & Ovoid & + & + & + & + & - & + & +++ & +++ & +++ & +++ & +++ & +++ & ++ \\
\hline $\mathrm{B}$ & Creamy & Ovoid & + & + & + & + & - & + & ++ & ++ & ++ & +++ & +++ & ++ & + \\
\hline $\mathrm{C}$ & Creamy & Ovoid & - & + & + & + & - & + & +++ & +++ & ++ & +++ & +++ & +++ & ++ \\
\hline $\mathrm{D}$ & Creamy & Ovoid & - & + & + & + & - & + & ++ & ++ & + & +++ & ++ & ++ & + \\
\hline E & Creamy & Ovoid & + & + & + & + & - & + & +++ & +++ & +++ & +++ & +++ & +++ & - \\
\hline
\end{tabular}

Key: Intensive growth (+++), Moderate growth (++), Low growth (+), No growth or response (-), Glu(glucose), Gal(galactose), Mal (maltose), Raf (raffinose), Lac, (lactose), Suc (sucrose).

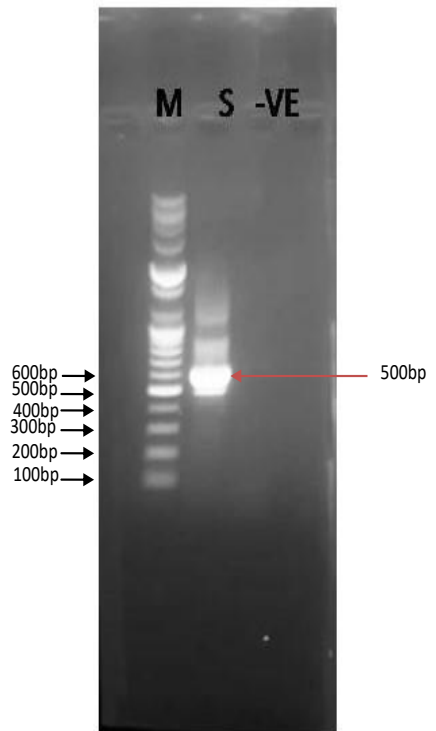

Fig. 2. Agarose Gel Electrophoresis of the Isolate A (Saccharomyces cerevisiae).

TABLE II: SEQUENCING AND BLAST ANALYSIS OF ISOLATE A

\begin{tabular}{cc} 
Organism & Isolate A \\
GenBank Relative & Saccharomyces cerevisiae \\
Accession Number & GU080045.1 \\
Coverage & $99 \%$ \\
E-Value & $2 \mathrm{e}-161$ \\
Identity & $88.65 \%$ \\
Accession Length & 594 \\
\hline
\end{tabular}

\section{B. Proximate Composition of Roselle Calyx Extract}

Table III shows the proximate composition of roselle calyces on dry weight basis. The result showed that moisture content of roselle calyx was $8.55 \%$ while the crude protein content was $6.10 \%$. The crude fat, crude fibre, ash content and carbohydrate content were $3.4 \%, 9.5 \%, 9.2 \%$ and $63.25 \%$, respectively.

TABLE III: PROXIMATE COMPOSITION OF ROSELLE CALYX EXTRACT

\begin{tabular}{cc}
\hline Parameters & Values $(\%)$ \\
\hline Moisture Content & 8.55 \\
Crude Protein & 6.1 \\
Crude Fat & 3.4 \\
Crude Fibre & 9.5 \\
Ash Content & 9.2 \\
Carbohydrate & 63.25 \\
\hline
\end{tabular}

\section{Physicochemical Changes During Fermentation}

The result in Table IV shows that the $\mathrm{pH}$ decreased from an initial value of $3.03 \pm 0.04$ on day 0 to a final $\mathrm{pH}$ of
$2.705 \pm 0.01$ at the end of the fermentation process, but a significant difference $(\mathrm{p}<0.05)$ was observed from the day 4 to day 10 of the fermentation process. Total soluble solids significantly decreased during fermentation process from an initial value of $20.35 \pm 0.49{ }^{\circ}$ Brix on day 0 to $15.87 \pm 0.35^{\circ}$ Brix at the end of fermentation. Alcohol content showed a steady increase in percentage as the fermentation progressed; the increase was from an initial undetectable value at day 0 to a value of $2.69 \pm 0.50 \%$ at the end of fermentation. A significant difference $(\mathrm{p}<0.05)$ was observed from day 6 to day 10 of fermentation process. Total titratable acidity significantly increased from $0.35 \pm 0.02$ to $1.15 \pm 0.03 \%$ during the fermentation process.

TABLE IV: PHYSICOCHEMICAL CHANGES DURING FERMENTATION

\begin{tabular}{ccccc}
\hline Day & $\mathrm{pH}$ & Alcohol $(\%)$ & $\begin{array}{c}\text { Titratable } \\
\text { Acidity }(\%)\end{array}$ & $\begin{array}{c}\text { Total soluble } \\
\text { solid }\left({ }^{\circ} B r i x\right)\end{array}$ \\
\hline 0 & $3.030 \pm 0.04$ & $0.00 \pm 0.00$ & $0.35 \pm 0.02$ & $20.35 \pm 0.49$ \\
2 & $2.940 \pm 0.04^{\mathrm{a}}$ & $1.50 \pm 0.38^{\mathrm{a}}$ & $0.47 \pm 0.01^{\mathrm{b}}$ & $18.40 \pm 0.14^{\mathrm{b}}$ \\
4 & $2.865 \pm 0.02^{\mathrm{b}}$ & $1.41 \pm 0.41^{\mathrm{a}}$ & $0.76 \pm 0.01^{\mathrm{b}}$ & $17.96 \pm 0.20^{\mathrm{b}}$ \\
6 & $2.825 \pm 0.01^{\mathrm{b}}$ & $1.98 \pm 0.59^{\mathrm{b}}$ & $0.83 \pm 0.01^{\mathrm{b}}$ & $16.97 \pm 0.54^{\mathrm{b}}$ \\
8 & $2.750 \pm 0.03^{\mathrm{b}}$ & $2.42 \pm 0.54^{\mathrm{b}}$ & $1.04 \pm 0.01^{\mathrm{b}}$ & $16.23 \pm 0.45^{\mathrm{b}}$ \\
10 & $2.705 \pm 0.01^{\mathrm{b}}$ & $2.69 \pm 0.50^{\mathrm{b}}$ & $1.15 \pm 0.03^{\mathrm{b}}$ & $15.87 \pm 0.35^{\mathrm{b}}$ \\
\hline
\end{tabular}

Values are Mean \pm SD for duplicate: a $(\mathrm{P}>0.05)$ and $\mathrm{b}(\mathrm{P}<0.05)$ as compared to Day 0.

\section{Effect of Fermentation on Antioxidant Activity of Roselle Calyx Aqueous Extract}

Total phenolic content of the fermented roselle calyx aqueous extract increased from 195.75 \pm 76.01 to $455.5 \pm 1.41 \mathrm{mgGAE} / 100 \mathrm{~g}$ dry extract and it differed significantly from the unfermented extract. Total flavonoid content increased from 193.0 \pm 74.25 to $291.5 \pm 4.95 \mathrm{mgQE} / 100 \mathrm{~g}$ dry extract but it did not differ from that of unfermented extract (Table V).

Table $\mathrm{V}$ shows that the DPPH radical scavenging activity of the fermented extract increased from $44.1 \%$ to $71.10 \%$ and a significant difference was observed as compared to the unfermented roselle aqueous extract. The total monomeric anthocyanin content of the fermented extract decreased from an initial value of $3518 \pm 30.8$ to $1075.0 \pm 28.2 \mathrm{CGE} / 100 \mathrm{~g}$ dry extract and also a significant difference was observed as compared to the unfermented roselle aqueous extract. The ascorbic acid content of the fermented extract increased from $1392 \pm 101$ to $2028 \pm 108 \mathrm{mgAAE} / 100 \mathrm{~g}$ dry extract and it differed significantly from the unfermented roselle calyx extract.

\begin{tabular}{|c|c|c|c|c|c|}
\hline $\begin{array}{c}\text { Sample (Roselle } \\
\text { Aqueous Extract) }\end{array}$ & $\begin{array}{c}\text { TPC } \\
\text { (mgGAE/100 g dry } \\
\text { extract) }\end{array}$ & $\begin{array}{c}\text { TFC (mgQE/100 g } \\
\text { dry extract) }\end{array}$ & $\begin{array}{l}\text { A.S (mgA.S/100 g } \\
\text { dry extract) }\end{array}$ & $\begin{array}{c}\text { TMAs (mgCy-3-O- } \\
\text { GE/100 g dry } \\
\text { extract) }\end{array}$ & DPPH (\%) \\
\hline Unfermented & $195.75 \pm 76.01$ & $193.0 \pm 74.25$ & $1392 \pm 101$ & $3518 \pm 30.8$ & $44.15 \pm 0.07$ \\
\hline Fermented & $455.5 \pm 1.41^{\mathrm{b}}$ & $291.5 \pm 4.95^{\mathrm{a}}$ & $2028 \pm 108^{b}$ & $1075.0 \pm 28.2^{\mathrm{b}}$ & $71.10 \pm 3.82^{b}$ \\
\hline
\end{tabular}

Values are mean \pm SD for duplicate; $\mathrm{a}(\mathrm{P}>0.05), \mathrm{b}(\mathrm{P}<0.05)$ as compared to unfermented. TPC (Total phenolic content), TFC (Total flavonoid content), TMA (Total monomeric anthocyanins), AS (Ascorbic acid content), DPPH (1-1-diphenyl-2- picryl hydrazy) scavenging activity. 


\section{DISCUSSION}

Earlier reports have confirmed that local beverages are good sources of Saccharomyces cerevisiae [19], [20]. Bakare et al. [4] documented that Saccharomyces cerevisiae isolated from palm wine have high tolerance to ethanol. The result of this study agrees with the work of Kurtzman and Fell [21] who stated that Saccharomyces cerevisiae isolated from palm wine have ovoid shape, creamy colour and ability to ferment sugars. Chi and Ameborg [22] reported that ethanol is one of the most important stress conditions that can affect yeast due to its high amount produced during fermentation. This study also revealed that Saccharomyces cerevisiae could tolerate ethanol at different concentrations and survive at varied temperature. Similarly, Querol [23] confirmed that wine yeast could adapt and survive under some stressful conditions of fermentation.

In this study, all the yeast isolates fermented all the sugars except lactose. The inability to ferment lactose could be due to lack of lactase enzyme which can breakdown lactose during sugar fermentation. This result is similar to the findings obtained by Umeh et al. [2].

Flocculation is an important feature that enables an easy separation of finished product which helps to reduces cost of centrifugation process. The work of Thias et al. [13] entitled 'Isolation and Characterization of Saccharomyces cerevisiae strains of winery interest', revealed that Saccharomyces cerevisiae have flocculation ability, which is similar to the result of this study.

The steady decline in $\mathrm{pH}$ during the fermentation process of the roselle extract could be attributed to the uptake of nutrients such as ammonium ions and the release of organic acids into medium, thus increasing the acidity of the extract. The finding of Lanchakon et al. [24] affirms that the decrease in total soluble solids during fermentation process could be linked to the consumption of sugars present in the medium by the fermenting yeast for growth and metabolism. Alcohol content showed a steady increase as the fermentation progressed; the progressive increase is due the conversion of sugars to alcohol by the yeast. The rise in total titratable acidity during the fermentation is due to the decrease in $\mathrm{pH}$ of the medium [24].

Phenolic compounds and flavonoids are materials that are spread throughout in plants due to secondary metabolism. Scientific research has revealed that roselle calyces are rich in polyphenols and flavonoids that enhance the nutritive value of roselle as these compounds are correlated to their antioxidant property [25]. Nazarni et al. [26] reported that total phenolic content (TPC) and total flavonoid content (TFC) determined using Folin-ciocalteu and Aluminium chloride colorimetric methods respectively, generally increase during fermentation of Tigarum flower, and this finding is in agreement with the results of this study. This finding also agrees with Fahad et al. [27], as they adopted similar methods and reported an increase in TPC and TFC after the fermentation of five varieties of grape leaves. More so, Tijana et al. [28] adopted similar method and reported an increase in TPC on fermentation of selected cereals and pseudo-cereals using Saccharomyces cerevisiae. Wang et al. [29] stated that the total phenols present in plant material improve after undergoing the process of fermentation and that the activity of antioxidant could be linked to the increase in the total phenolic compounds. A report from Verzelloni et al. [30] had also emphasized that the capability of antioxidants in wine and vinegar is linked to the total amount of phenols present. During fermentation, phenols bearing high molecular weight are usually broken down into their simpler form [1].

Saccharomyces cerevisiae fermentation significantly enhanced the scavenging activity of roselle calyx aqueous extract from $44.15 \%$ to $71.10 \%$ in this study. This result is in agreement with the findings obtained by Jirasak [31] who reported that fermentation is an improved technique for procuring greater amount antioxidant in Roselle. The total activity of antioxidants could be a consequence of many antioxidants that are present in the extract [32]. The improved activity of antioxidants in this study could be that Saccharomyces cerevisiae caused changes in total phenolic content (TPC) and total flavonoid content (TFC) of the extract during the fermentation reaction. Most fungi are known to possess the ability to produce antioxidants. During biochemical reactions that involves fermentation, fungi are able to release enzymes that can breakdown the glucosidic linkages of some hydroxyl group of phenols that are joined to sugar compounds and this degradation in turns increases the amount of free phenols, thus increasing bioactivity of food material [33], [34].

The total monomeric anthocyanin (TMA) content of the extract which significantly decreased at the end of fermentation, may be attributed to the fact that anthocyanin is sensitive and can be easily broken down in the presence of heat, light, oxygen, enzymes, pH etc. [35]. Ruth et al. [36] reported similar decrease in the total and individual anthocyanin concentration by fermentation process of strawberry wine and strawberry vinegar. The decrease could be due to the $\mathrm{pH}$ change of the extract during the fermentation process. Anthocyanin retention is largely affected by changes in $\mathrm{pH}$ [37]. The amount of ascorbic acid of the extract increased at the end of the fermentation process. This result is similar to the findings of Nwafor and Akpomie [38] who reported a similar increase in ascorbic acid content of Roselle drink upon fermentation by Saccharomyces cerevisiae.

\section{CONCLUSION}

The study revealed that Roselle calyx aqueous extract contain phenols, flavonoids and ascorbic acid, and they exert antioxidant activities in the extract. Also, this study showed that Saccharomyces cerevisiae-induced fermentation increased the amount phenols, flavonoids and ascorbic acid in the reaction medium, thus improving its antioxidant activity. It can be concluded that Roselle calyx aqueous extract is a good source of antioxidants and fermentation is a better means of improving the antioxidant status of Roselle extract. This study recommends a laboratory test of the fermented Roselle extract on animals, and the molecular identification of genes responsible for antioxidant activity of Roselle calyx. 


\section{ACKNOWLEDGMENT}

I would like to appreciate Dr. P.A Vantsawa, the Head of Department of Biological Sciences, Nigerian Defence Academy, who provided the platform for the conduct of this research. The input of Dr. (Mrs) N. Egbe was so invaluable. I also acknowledge Mrs R.A. Idrees of the Department of Biochemistry, Kaduna State University, for her support. Other scholars from Ahmadu Bello University and DNA LABS, who made some useful suggestions are appreciated.

\section{REFERENCES}

[1] J.H. Sun, Y.L. Seung, K. Young-Chan,C. Inwook and K. Geun-Bae. (2014). Effect of fermentation on the antioxidant activity in plant-based foods. Food Chemistry, 160:346-356.

[2] S.O. Umeh, L.C. Agwuna and U.C. Okafor. (2017). Yeast from local sources: An alternative to conventional brewer's yeast. International Journal of Biotechnology and Food Science 30:191-195.

[3] P. Saranraj, P. Sivasakthivelan and M. Naveen. (2017). Fermentation of Fruit Wine and its Quality Analysis: A Review. Australian Journal of Science and Technology. 1: 85-96.

[4] V. Bakare, M.S. Abdulsalami, B.C. Onusiriuka, J. Appah, B. Benjamin and T.O. Ndibe. (2019). Ethanol production from lignocellulosic materials by fermentation process using yeast. Journal of Applied Science and Environmental Management 23: 875-882.

[5] T.A. Barhé and G.R.F. Tchouya. (2015). Comparative study of the antioxidant activity of the total polyphenols extracted from Hibiscus sabdariffa L., Glycine max L. Merr., yellow tea and red wine through reaction with DPPH free radicals. Arabian Journal of Chemistry, 9, 18.

[6] P. Kekungu-u, A. Chubasenla, G. Sandeep, D. Samir, S. Rajkumari, P.M. Kamal, K.J. Anjani, S. Ingudam and S. Arnab. (2017). Studies on the therapeutic properties of roselle (Hibiscus sabdariffa) calyx: A popular ingredient in the cuisine of North East India. International Journal of Food Science and Nutrition. 2(5):1-6.

[7] J. Kukic, S. Petrovic and M. Niketic. (2006). Antioxidant activity of four endemic Stachys taxa. Biological and Pharmaceutical Bulletin., 29: 725-729.

[8] S. S. Ogundapo, J.C. Onuoha, C.N. Olekanma, A.B. Okon, O.T. Soniran, D.A. Omoboyowa and D.A. Okor. (2014). Alteration in biochemical parameters of Hibiscus sabdariffacalyces (zobo) supplemented with commercial flavor additive. Journal of Natural Product. 7:116-123.

[9] T. Frank, N. Gabriele, R. Dietmar and C. Reinhold. (2012). Consumption of Hibiscus Sabdariffa L. aqueous extract and its impact on systematic antioxidant potential in healthy subjects. Journal of the Science of Food and Agriculture 92: 2207-18.

[10] AOAC (2010). Official Methods of Analysis, 18th edition Association of Official Analytical Chemist, Washington, DC.

[11] A.V. Martini and A. Martini. (1993). A Taxonomic key for genus Sacharromyces Systematic and Applied Microbiology 16(1): 113-119.

[12] J. Barnett, R. Payne and D. Yarrow. (2000) Yeast Characteristics and Identification. 3rd ed., Cambridge University Press, 1139-1145.

[13] M. Thais, D.G. Guimarães, I.P. Moriel, M.T. Machado, P. Cyntia, Fadel and T.B. Tania. (2006). Isolation and Characterization of Saccharomyces cerevisiae strains of winery interest. Brazilian Journal of Pharmaceutical Sciences, 42: 119-126.

[14] A.O.A.C. (2000). Official Methods of Analysis of the Association of Official Analytical Chemists 17th Ed. Published by the Association of Official Analytical Chemists. USA.

[15] K.B. Mgaya, S.F. Remberg, B.E. Chove and T. Wicklund. (2014). Physicochemical, mineral composition and antioxidant properties of roselle (Hibiscus sabdariffa) extract blended with tropical fruit juices. African Journal of Food, Agriculture, Nutrition and Development. 14(3): 112-119.

[16] J. Zhishen, T. Mengcheng and W. Jianming. (1999). The determination of flavonoid contents in mulberry and scavenging effects on superoxide radicals. Food Chemistry, 64: 555-559.

[17] S.G. Claudia, T. Fidel, B. Vergara, E. Ana, R. Ortega and A.G. Jose. (2012) Antioxidant properties and color of Hibiscus sabdariffa extracts. Ciencia. investigacion.Agraria. 39(1):79-90.
[18] K. Chakraborty, V. Saha, V. Raychaudhuri and R. Chakraborty. (2015). Optimization of bioprocessing parameters using response surface methodology for bael (Aegle marmelos L.) wine with the analysis of antioxidant potential, colour and heavy metal concentration. Nutrafoods, 14(1): 39-49. http://dx.doi.org/10.1007/s13749-014-00648.

[19] V.A. Jideani, I. Nkem, E.B. Agbo and I.A. Jideani. (2001). Survey of production in some Northern States of Nigeria. Plant Foods for Human Nutrition. 14: 23- 36

[20] S.O. Umeh, O. Udemezue, B.C. Okeke and G.C. Agu. (2015). Paw paw (Carica papaya) wine: with low sugar produced using Saccharomyces cerevisiae isolated from a local drink'burukutu". International Journal of Biotechnology and Food Science. 5(2):17-22.

[21] C.P. Kurtzman and J.W. Fell. (1999). The yeasts. A taxonomic study. North-Holland, Amsterdam 1055

[22] Z. Chi and N. Ameborg. (2000). Saccharomyces cerevisiae strains with different degrees of ethanol tolerance exhibit different adaptive responses to produced ethanol. Journal of Industrial Microbiology and Biotechnology. 24: 75-78.

[23] A. Querol, E.M. Fernandez, M. Olmo and E. Barrio. (2003). Adaptive evolution of wine yeast. International Journal of Food Microbiology, 86: $3-10$

[24] C. Lanchakon, O. Nutwara, J. Chanjira and J. Maneewan. (2017) Scavenging Capacity and Antibacterial Activity Extract and Wine Production. Suan Sunandha and Technology Journal. Vol 4,17-22.

[25] R. Ghazala and C. Rajni. (2018). "A review on phytochemistry and therapeutic uses of Hibiscus sabdariffa L." Biomedicine \& Pharmacotherapy. 102:575-586.

[26] R. Nazarni, D. Purnama, S. Umar and H. Eni. (2016). The effect of effection on total phenolic, flavonoid a nd tannin content and its relation to antibacterial activity in jaruk tigarun (Crataeva nurvala, Buch HAM). International Food Research Journal 23:309-315.

[27] A. Fahad, U. Nurhan, M. Mehmet, G. Mehmet, A. Isam, A. Hesham and A. Magdi and A. Mustafa. (2019). Effect of fermentation on antioxidant activity and phenolic compounds of the leaves of five grape varieties. Journal of Food Processing and Preservation 43: 234-237.

[28] M.D. Tijana, S.S. Slavica and I.D. Suzana. (2010). Effect of fermentation on the antioxidant properties of some cereals and pseudocereals. Food Chemistry 119:957-963.

[29] N. Wang, C. Wang, Y. Tzeng and Y. Shyu. (2011). Lactic acid bacterial fermentation on the production of functional antioxidant herbal Anoectochilus formosanus Hayata. Journal of Bioscience and Bioengineering 111: 289-293.

[30] E. Verzelloni, D. Tagliazucchi and A. Conte. (2007). Relationship between the antioxidant properties and the phenolic and flavonoid content in traditional balsamic vinegar. Food Chemistry, 105(2), 564571.

[31] K. Jirasak. (2015). Enhancement of bioactive compounds of roselle vinegar by co-culture fermentation. Chemistry14:61-71.

[32] S.P.J. Senanayake. (2013). Green tea extract: Chemistry, antioxidant properties and food applications-A review. J. Funct. Foods 5, 15291541.

[33] S.R. Georgetti, F.T. Vicentini, C.Y. Yokoyama, M.F. Borin, A.C Spadaro and M.J. Fonseca. (2009). Enhanced in vitro and in vivo antioxidant activity and mobilization of free phenolic compounds of soybean flour fermented with different beta-glucosidase-producing fungi. Journal of Applied Microbiology, 106(2), 459-466.

[34] S. Cai, O. Wang, W. Wu, S. Zhu, F. Zhou, B. Ji., et al. (2012) Comparative study of the effects of solid-state fermentation with fhree filamentous fungi on the total phenolics content (TPC), flavonoids, and antioxidant activities of subfractions from oats (Avena sativa L.) Journal of Agricultural and Food Chemistry, 60(1), 507-513.

[35] W. Hai-Yao, Y. Kai-MIN and C. Yuan. (2018). Roselle anthocyanin: Antioxidant properties and stability to heat and $\mathrm{pH}$. Department of Food Science and Biotechnology. Molecules 23:135.

[36] H.O. Ruth, M. Antonia, B.C. Ana. And G. Isidoro. (2017). Influence of fermentation process on anthocyanin composition of wine and vinegar elaborated from strewberry: Anthocyanins in strewberry wine and strewberry vinegar. Journal of Food Science 82.

[37] D. Tagliazucchi, E. Verzelloni, D. Bertolini and A. Conte. (2010). In vitro bio-accessibility and antioxidant activity of grape polyphenols. Food Chemistry, 120(2), 599-606.

[38] E.O. Nwafor and O.O. Akpomie. (2014). Effect of fermentation time on quality attributes of zovo drink prepared from Hibiscus sabdariffa Linn. International Journal of Food Nutritional Safety 5(1):16-23. 